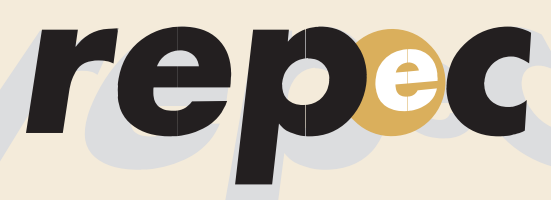

REPeC, Brasília, v. 8, n. 2, art. 2, p. 142-158, abr.jun. 2014 Disponível online em www.repec.org.br
Revista de Educação e Pesquisa em Contabilidade

Journal of Education and Research in Accounting

Revista de Educación e Investigación en Contabilidad

Periódico Trimestral, digital e gratuito publicado pela Academia Brasileira de Ciências Contábeis

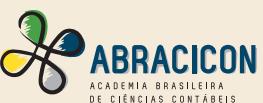

\title{
Uma Aplicação da Técnica Delphi no Mapeamento das Dimensões das Qualificações Docentes na Área Contábil
}

\author{
Resumo \\ A avaliação das qualificações docentes tem sido um tema \\ recorrente na literatura e não sem controvérsias. Este estudo \\ se propõe a conhecer e analisar as percepções de um grupo \\ de especialistas da área contábil sobre as dimensões das \\ qualificações docentes consideradas essenciais na educação \\ superior contábil na contemporaneidade, utilizando-se da \\ técnica Delphi. Para tanto, foi formada uma comissão de \\ 21 especialistas nacionais e estrangeiros, com formação \\ heterogênea, representativa das dimensões da qualificação \\ docente que se pretendia analisar. Foram necessárias três \\ rodadas para que se atingisse o consenso. Os resultados \\ indicaram que a qualificação acadêmica ficou composta por \\ fatores relativos à titulação, pesquisa e publicação; a qualificação \\ profissional por fatores relativos à experiência profissional e \\ credenciais; e a qualificação pedagógica por fatores relacionados \\ ao apoio institucional, experiência no ensino e formação \\ continuada. Também pode ser verificado que a formação \\ acadêmica é a formação mais valorizada pela comissão \\ completa, alcançando $46,7 \%$ dos especialistas pesquisados.
}

Palavras-chave: Ensino. Contabilidade. Qualificações docentes. Técnica Delphi.

\begin{abstract}
Gilberto José Miranda
Doutor em Controladoria e Contabilidade (USP) e Professor da Universidade Federal de Uberlândia. Contato: Av. João Naves de Ávila, 2.121, Santa Mônica, Uberlândia, MG, CEP: $38.400-902$.

E-mail: gilbertojm@facic.ufu.br
\end{abstract}

Silvia Pereira de Castro Casa Nova Pós-Doutorado em Contabilidade (EAESPFGV) e Professora da Universidade de São Paulo. Contato: Av. Prof Luciano Gualberto, 908, Cidade Universitária, São Paulo, SP, CEP: 05508-010.

E-mail: silvianova@usp.br

Edgard Bruno Cornacchione Junior Livre docente e Doutor em Ciências Contábeis pela USP, Ph.D. em Educação pela Universidade de Illinois e Professor titular da Universidade de São Paulo. Contato: Av. Prof. Luciano Gualberto, 908, Cidade Universitária, São Paulo, SP, Brasil, CEP: 05558-010.

E-mail: edgardbc@usp.br 


\section{Introdução}

A formação de professores para atuação no ensino superior tem sido objeto de muitas pesquisas na atualidade (Frecka \& Reckers, 2010; Marshall, Dombrowski, Garner \& Smith, 2010; Miranda, 2010; Almeida \& Pimenta, 2009; Andere \& Araújo, 2008; Slomski, 2009; Shulman, 2005; 1986) e vários aspectos da referida formação vêm sendo discutidos. No campo da Contabilidade, por exemplo, discutem-se: a relevância do preparo para o exercício da pesquisa, notadamente, por meio da obtenção de titulação stricto sensu; a importância do contato com práticas exercidas no mercado profissional; e a relevância dos conhecimentos didático-pedagógicos.

Os professores do ensino superior, em geral, não passam por uma preparação pedagógica sistematizada para o exercício da docência. No campo das licenciaturas, os currículos contemplam disciplinas relacionadas a conteúdos didático-pedagógicos. Os bacharéis, no entanto, têm acesso a esses conteúdos quanto optam por cursarem disciplinas relacionadas à metodologia do ensino superior, em programas de pós-graduação stricto sensu, ou quando buscam formação na área educacional. Para Pierre, Wilson, Ravenscroft \& Rebele (2009, p. 126), a literatura educacional é uma fonte riquíssima de conhecimentos que poderão ser consultados e utilizados pelos docentes da área contábil. Entretanto, para que haja desenvolvimento dos programas de Contabilidade, em seus diversos níveis, é importante que a construção de conhecimentos considere as especificidades da área contábil, pois a base epistemológica faz com que as práticas pedagógicas sejam diferentes entre as áreas do conhecimento.

Fora do Brasil, as discussões mais acirradas recaem sobre a qualificação acadêmica e a qualificação profissional. Para muitos autores, as duas qualificações são essenciais para a eficácia do professor de Contabilidade (Njoku, Heijden \& Inanga, 2010; Heijden, 2003). Muito embora se reconheça que exigir as duas qualificações, a um mesmo docente, torna a sua formação mais complicada, e que o ideal é que o corpo docente da instituição seja composto por professores detentores de ambas as qualificações, de modo que o estudante possa ter contato com os dois tipos de formação durante a graduação.

No exterior, essa discussão está mais amadurecida, porém, no cenário brasileiro, ela ainda é incipiente, o que pode ser constatado: (a) pela baixa quantidade de pesquisa e pesquisadores investigando o tema; (b) pela própria quantidade de professores com condições de alcançar os níveis de qualificação acadêmica estabelecidos no exterior, como os critérios da The Association to Advance Collegiate Schools of Business (AACSB), por exemplo. No Brasil, a quantidade de doutores em Ciências Contábeis é pouco superior a duzentos, enquanto nos Estados Unidos, em 2008, já chegava a 7.109 titulados (Bouillon \& Ravenscroft, 2010); e (c) pelo pouco avanço, em termos profissionais, o Exame de Suficiência do Conselho Federal de Contabilidade (CFC), que poderá fortalecer a credencial profissional, é ainda muito recente, enquanto nos Estados Unidos o Certified Public Accountants (CPA) está consolidado ao lado de diversas credenciais específicas como CMA (Certified Management Accountant), Chartered Financial Analyst (CFA) e outras, que são complementadas por experiências relevantes sobre o assunto ministrado nas aulas.

Diante desse cenário, é extremamente complexo estabelecer as qualificações docentes necessárias ao professor que ensina Contabilidade. Nesse sentido, levanta-se a seguinte questão: Quais são as percepções de um grupo de especialistas da área contábil sobre as dimensões das qualificações docentes consideradas essenciais na educação superior contábil na contemporaneidade?

Para alcance desse propósito, realizou-se uma incursão na literatura sobre a formação docente no ensino superior e a formação do professor de Contabilidade tanto no Brasil quanto no contexto internacional, a fim de evidenciar quais qualificações e seus respectivos fatores compõem a formação do professor contador. Posteriormente, essas informações foram submetidas a uma comissão de especialistas nacionais e estrangeiros para serem confirmadas por meio da técnica Delphi. Além dos fatores de avaliação do desempenho docente validados pelos especialistas, faz-se uma exploração de diferenças entre as subcomissões (contadores brasileiros, contadores estrangeiros, outras áreas - Administração e Educação) que compuseram o painel de especialistas. Uma análise complementar interessante implementada foi contrastar os posicionamentos de especialistas estrangeiros e brasileiros, o que pode fornecer subsídios para a análise dos diferentes estágios de desenvolvimento da área de conhecimento no Brasil e no exterior. 


\section{Plataforma Teórica}

Vários estudos procuraram mapear, entre os estudantes e os professores, os atributos dos professores que se destacam de forma positiva em sala de aula (Volpato, 2009; Marshall et al., 2010; Slomski \& Martins, 2008; Catapan, Colauto \& Sillas, 2011; Miranda, Casa Nova \& Cornacchione, 2012). Volpato (2009, p. 335) realizou uma pesquisa para compreender as representações e práticas pedagógicas em cursos que, tradicionalmente, formam profissionais liberais, como Medicina, Direito e Engenharia. Segundo o autor, “[...] ficou evidente que há uma convergência no entendimento de que o professor com 'boa didática' é aquele capaz de 'relacionar teoria e prática', com capacidade de trazer fatos concretos do campo profissional para serem pensados e analisados em sala de aula", pois, de acordo com os estudantes, "o professor atuante no campo profissional tem melhores condições de apresentar e socializar os conteúdos da disciplina, porque é capaz de fazer relação de forma mais concreta com base em suas experiências, tornando-os mais fáceis de serem compreendidos." (Volpato, 2009, p. 339). Isso significa que, na visão dos estudantes pesquisados, o professor com "boa didática" é aquele que tem experiência profissional e consegue trazer essa vivência para a sala de aula.

Nessa mesma linha, Marshall et al. (2010) realizaram uma pesquisa sobre o ensino da Contabilidade com 95 professores americanos de Contabilidade (doutores e detentores da credencial CPA). Os autores verificaram que, segundo os respondentes, não há qualificação que substitua a experiência no ensino e na prática contábil quando se pretende tornar um professor de Contabilidade eficaz. Para Slomski e Martins (2008) no Brasil, em vista das limitações no que se refere à formação profissional para o magistério, é a própria experiência na profissão, na sala de aula e na universidade e a experiência dos pares que vêm estruturando e dando sentido à prática pedagógica dos professores de Contabilidade.

Catapan et al. (2011), fundamentados no Modelo Bidimensional de Efetividade de Ensino de Lowman (2007), realizaram um estudo com a finalidade de analisar as principais práticas e atributos dos professores de Contabilidade que possuem êxito em sala de aula do ponto de vista de 234 discentes de universidades públicas e privadas de Curitiba (PR) e Joinvile (SC). Os achados apontam o domínio de conteúdo, a clareza ao transmitir as informações e o despertar para o interesse na aula como as razões do bom desempenho docente. Em relação à dimensão "estímulo intelectual", os adjetivos que definem um bom docente são "preparado", "claro" e "organizado". Na dimensão "relacionamento interpessoal", os adjetivos citados foram "respeitoso" e "interessado".

Miranda et al. (2012) também realizaram uma pesquisa com o propósito de avaliar os saberes predominantes nos docentes percebidos como professores-referência, pelos alunos de um curso de graduação em Ciências Contábeis de uma universidade pública brasileira. Dentre os principais achados, destacam-se: (a) as disciplinas responsáveis pelas experiências mais significativas de aprendizagem durante o curso eram aquelas percebidas como base do curso e que apresentaram maior aplicação prática; e (b) as razões principais para escolha dos docentes-referências foram didática ou metodologia de ensino e as atitudes e qualidades pessoais do professor. Os três saberes decorrentes dessas escolhas foram, nesta ordem, conhecimento didático, domínio do conteúdo e saberes experienciais.

Os estudos acima elencados e outros adiante mencionados apontam para a necessidade de pelo menos três tipos de qualificações ao docente que ensina Contabilidade: (a) qualificação acadêmica; (b) qualificação profissional; e (c) qualificação pedagógica, conforme apresentado na Figura 1. 


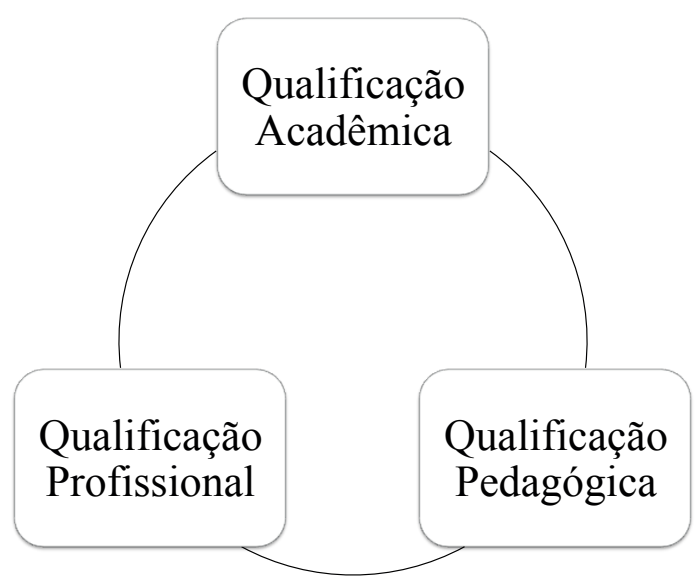

Figura 1. Dimensões da Qualificação Docente em Ciências Contábeis

Fonte: os autores

A Qualificação Acadêmica (Qac) refere-se à preparação do docente para o exercício da pesquisa sobre os temas que leciona. Vários autores destacam a importância da titulação e da pesquisa no exercício da docência em Contabilidade, dentro e fora do Brasil (Njoku et al., 2010; Ruff, Thibodeau \& Bedard, 2009; Pierre et al., 2009; Libâneo, 2009; Cunnigham, 2008; Annisette \& Kirkham, 2007; Kachelmeier, 2002). No exterior, esse tipo de qualificação, normalmente, ocorre quando o docente tem o título de doutor e pesquisas relevantes sobre os temas que leciona.

Já a Qualificação Profissional (Qpr) indica a ligação do docente com as práticas contábeis vigentes no campo profissional, ou seja, o professor tem um "pé" na academia e "outro" no mercado (Marshall et al., 2010; Geary, Kutcher \& Porco, 2010; Njoku et al., 2010; Harmer, 2009; Volpato, 2009; Miley, 2009; Trapnell, Mero, Williams \& Krull Jr., 2009; Annisette \& Kirkham, 2007). No cenário internacional, essa qualificação é formalizada por meio da titulação de mestrado e de uma credencial profissional, como CPA, CMA, CFA e outras, complementadas por experiências relevantes sobre o assunto ministrado nas aulas.

Finalmente, a Qualificação Pedagógica (Qpe) representa a preparação sistematizada para o exercício da docência, estando relacionada com o domínio didático-pedagógico, metodologias de ensino da Contabilidade e políticas e programas de apoio à formação contínua do quadro docente mantido pela Instituição de Ensino Superior (IES) ou pelo curso de Ciências Contábeis. A ausência dessa qualificação no ensino superior, de modo geral, tem sido alvo de fortes críticas por partes de estudiosos da área educacional e também da área contábil (Frecka \& Recka, 2010; Marshall et al., 2010; Miranda, 2010; Almeida \& Pimenta, 2009; Andere \& Araújo, 2008; Slomski, 2009; Shulman, 2005; 1986). Por outro lado, referências na área têm enfatizado que a qualificação pedagógica é meio e que "quem tem um porquê, arruma um como." (Machado, 2011).

A partir do referencial teórico construído pelo exame da literatura, a pesquisa encaminha-se para uma etapa de resultados da investigação ao painel de especialistas por meio da técnica Delphi.

\section{Método}

Este se estudo se classifica como pesquisa exploratória de cunho quantitativo. Nesse sentido, inicialmente, buscou-se identificar, na plataforma teórica, os fatores que constituem as qualificações dos docentes de Contabilidade. Posteriormente, esses foram categorizados em qualificação acadêmica, qualificação profissional e qualificação pedagógica. Finalmente, os referidos fatores foram confirmados pela técnica Delphi, uma técnica científica que permite analisar dados qualitativos com o objetivo de formar um consenso entre especialistas no assunto investigado (Grisham, 2009; Giovinazzo, 2001). Nesse sentido, Fink, Kosecoff, Chassin, \& Brook (1984) afirmam que os métodos de consenso formal têm como principal objetivo definir níveis de concordância em termos controversos. 
A aplicação da técnica Delphi teve o objetivo de confirmar se os fatores da qualificação docente levantados na literatura compulsada eram os julgados relevantes na opinião dos especialistas, para, com base nos fatores apurados, efetuar um mapeamento das qualificações docentes nos cursos de graduação em Contabilidade no Brasil.

\subsection{A técnica Delphi}

A técnica Delphi foi desenvolvida no final dos anos 1940, com base nos trabalhos de Olaf Helmer e Norman Dalker, pesquisadores da Rand Corporation, para fins militares. A partir dos anos 1960, essa técnica passou a ser bastante disseminada. Czinkota \& Ronkainen (2005) indicam que a técnica Delphi tem ganhado a aceitação substancial em várias áreas do saber. Esses autores relatam que essa técnica tem sido utilizada como uma ferramenta de pesquisa nas áreas de Biblioteconomia, Ciência da Informação, disciplinas médicas, estudos plurinacionais, previsão de condições econômicas, entre outros. Além disso, segundo os autores, o método produz resultados úteis, aceitos e suportados pela maioria da comunidade científica. Grisham (2009) afirma que, em uma pesquisa da Academic Search Premier, em maio de 2008, foram identificados 476 artigos que se utilizaram da técnica Delphi, o que indica ser o uso dessa técnica na pesquisa uma prática bastante aceita.

Segundo Grisham (2009), o método requer a participação de colaboradores que sejam especialistas na área, os quais respondem, individualmente, às questões propostas, submetendo os resultados a um coordenador central que processa as respostas, observa tendências e discrepâncias e suas justificativas. Os resultados, então, são devolvidos aos respondentes. Ao tomar conhecimento dos resultados, os inquiridos podem mudar suas opiniões para reenvio ao coordenador, em um processo contínuo, até que o consenso seja formado.

Nesse sentido, Vianna (1989) entende que o número de rodadas depende da estabilidade, ou seja, quando não surgirem novas contribuições para o estudo. Nessa pesquisa, para estabelecer o fim das rodadas, foi utilizado o cálculo do coeficiente de variação das respostas (quociente entre desvio padrão e média) associado a uma regra de decisão: (a) quociente menor que 15\%: baixa dispersão; (b) quociente maior que $15 \%$ e menor que 30\%: média dispersão; (c) quociente maior que 30\%: elevada dispersão (Martins \& Theóphilo, 2007). Foram necessárias três rodadas para se atingir a estabilidade, isto é, coeficiente de dispersão menor que $30 \%$ para a maioria das variáveis.

\subsection{Seleção dos Especialistas}

É importante selecionar um painel de especialistas que esteja balanceado em termos de imparcialidade e interesse no assunto (Grisham, 2009). Neste estudo, o termo "especialista" significa indivíduo com notório saber, além de experiência e titulação comprovada, ligado a instituições acadêmicas e profissionais que têm interface com o ensino de Ciências Contábeis (associações de credibilidade, entidades governamentais reguladoras do ensino superior e pós-graduação, representantes de órgãos internacionais relacionados ao ensino de Ciências Contábeis, representantes de órgãos de classes e professores de Educação, Administração e Ciências Contábeis).

O número de especialistas recomendado é bastante divergente entre os autores, sendo apontadas quantidades que variam de 10 a 60 membros (Vianna, 1989; Giovinazzo, 2001; Grisham, 2009). Neste estudo, foram convidados 43 especialistas (26 aceitaram o convite) e 21 completaram todas as rodadas (48,8\% dos convidados). A diversidade de profissionais é alta, conforme recomendado pela literatura. Em termos de formação, a maioria dos especialistas são professores pós-doutores em programas de mestrado e doutorado, sendo 14 membros com formação na área de Ciências Contábeis, quatro com formação em Educação e três na área de Administração. Em termos de nacionalidade, quatro são americanos, um escocês e dezesseis brasileiros. A Figura 2 sintetiza outras características relacionadas às filiações acadêmicas e profissionais da comissão relevantes a este estudo. 


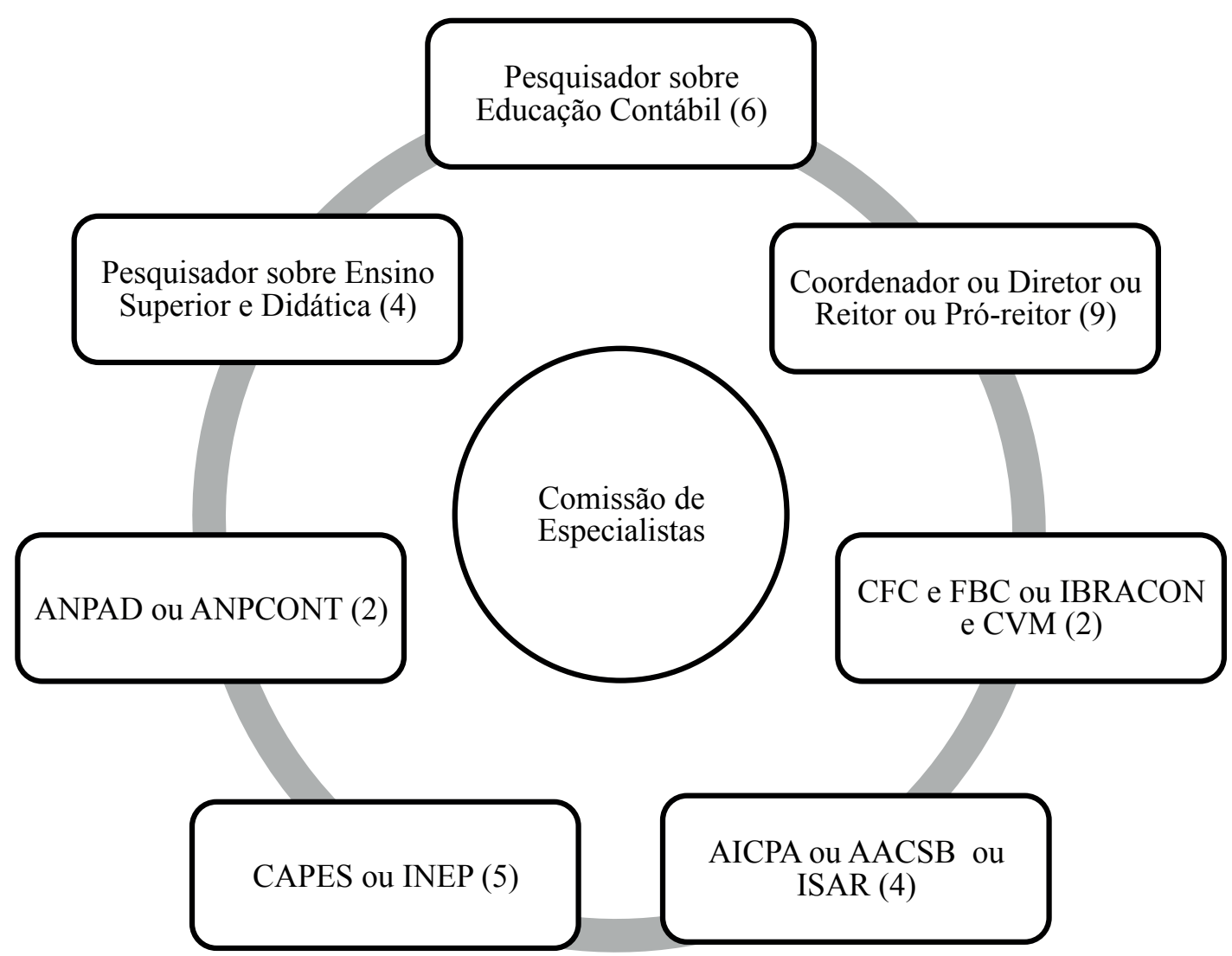

Figura 2. Principais Atributos dos Membros da Comissão de Especialistas

É importante ressaltar que a comissão contempla especialistas detentores das três qualificações investigadas neste estudo, quais sejam: qualificação acadêmica, qualificação profissional e qualificação pedagógica. Essa escolha foi feita considerando-se os objetivos da pesquisa, ou seja, identificou as relações entre qualificações docentes e desempenho discente. Entende-se que a ligação com a academia, a titulação e as pesquisas já empreendidas na área contábil e educacional sejam atributos importantes para que os especialistas possam refletir de forma embasada sobre os fatores componentes de cada uma das três qualificações. Todavia, a comissão não deixa de estar fortemente ligada à profissão contábil, pois existem quatro integrantes que atuam ou já atuaram em conselhos profissionais nacionais e estrangeiros (Conselho Federal de Contabilidade [CFC], Fundação Brasileira de Contabilidade [FBC], Instituto Brasileiro de Auditores Independentes [Ibracon], Comissão de Valores Mobiliários [CVM] e Instituto Americano de Contadores Públicos Certificados [AICPA]), um representante de Association to Advance Collegiate Schools of Business [AACSB] (instituição de credenciamento de cursos) e um representante do Intergovernmental Working Group of Experts on International Standards of Accounting and Reporting [ISAR] (instituição eminentemente técnica). Além disso, a maioria dos contadores e administradores componentes da comissão atua ou já atuou no mercado profissional, como contadores, consultores e gestores de instituições. Por fim, a comissão também apresenta estudiosos da área educacional para que os fatores relacionados à qualificação pedagógica possam ser adequadamente analisados. Portanto, a composição da comissão de especialistas foi feita mediante a consideração de pessoas qualificadas para analisar os conceitos de desempenho discente, qualificação acadêmica, qualificação profissional e qualificação pedagógica. 


\section{Resultados}

O processo foi realizado em três rodadas sucessivas, tendo iniciado no dia 26/5/2011, data de envio da primeira rodada, com término em 15/6/2011, data em que foi recebida a última resposta da terceira rodada.

Antes do início da primeira e segunda rodadas, foram feitos dois pré-testes nas versões eletrônicas do questionário, com a participação de quatro professores em cada uma delas, sendo dois professores do curso de Ciências Contábeis, com titulações de mestrado (um doutorando), e dois professores da área educacional, também com titulações de mestrado (um doutorando). Após a consideração das sugestões feitas durante o pré-teste, o instrumento foi finalizado.

\subsection{Primeira Rodada Delphi}

Na primeira rodada, foi apresentada aos especialistas, por meio de um questionário eletrônico, uma lista contendo 22 fatores relativos às qualificações acadêmica, profissional e pedagógica, definidos com base na literatura. Em seguida, foi solicitado aos especialistas que expressassem sua concordância ou discordância quanto aos fatores apresentados e a caracterização das qualificações. O percentual de aceitação dos fatores pelo grupo está expresso na Tabela 1.

Tabela 1

Percentual de Aceitação dos Fatores - Primeira Rodada Delphi

\begin{tabular}{|c|c|c|}
\hline Qualificação & Fatores & \% de Concordância \\
\hline \multirow{8}{*}{ Acadêmica } & Título de doutor & $81 \%$ \\
\hline & Título de mestrado & $90 \%$ \\
\hline & Título de especialista & $43 \%$ \\
\hline & Ser revisor de periódicos científicos ou parecerista. & $48 \%$ \\
\hline & Atuar em instituições de ensino superior com dedicação exclusiva. & $38 \%$ \\
\hline & $\begin{array}{l}\text { Possuir publicações em periódicos científicos internacionais ou com Qualis/ } \\
\text { CAPES = A1, A2, B1 ou B2. }\end{array}$ & $62 \%$ \\
\hline & Possuir publicações em outros periódicos científicos. & $86 \%$ \\
\hline & $\begin{array}{l}\text { Participação em associações ou órgãos de pesquisa (Exemplos: ANPAD, } \\
\text { ANPCONT, CAPES). }\end{array}$ & $71 \%$ \\
\hline \multirow{5}{*}{ Profissional } & Experiência de atuação na profissão contábil (mínima de dois anos). & $86 \%$ \\
\hline & Projetos de extensão envolvendo academia e comunidade. & $95 \%$ \\
\hline & Projetos de pesquisas aplicadas (academia/mercado). & $95 \%$ \\
\hline & $\begin{array}{l}\text { Participação em associações de classe ou órgãos reguladores (Exemplos: } \\
\text { Conselhos de Contabilidade, Comissão de Valores Mobiliários, Banco Central, } \\
\text { Comitê de Pronunciamentos Técnicos). }\end{array}$ & $48 \%$ \\
\hline & Consultorias, assessorias e pareceristas técnicos. & $81 \%$ \\
\hline
\end{tabular}




\begin{tabular}{llc}
\hline Qualificação & \multicolumn{1}{c}{ Fatores } & \% de Concordância \\
\hline & \multicolumn{1}{c}{$\begin{array}{l}\text { Curso de formação pedagógica stricto sensu (mestrado ou doutorado) em } \\
\text { Educação. }\end{array}$} & $43 \%$ \\
\cline { 2 - 3 } & Curso de formação pedagógica lato sensu (especialização) em Educação. & $57 \%$ \\
\cline { 2 - 3 } & Curso de extensão para formação pedagógica. & $81 \%$ \\
\cline { 2 - 3 } Pedagógica & Projetos de pesquisas relacionados ao ensino. & $67 \%$ \\
\cline { 2 - 3 } & Experiência como docente (mínimo de dois anos). & $76 \%$ \\
\cline { 2 - 3 } & $\begin{array}{l}\text { Oferta de programas de preparação para docência Centro de Apoio Pedagógico } \\
\text { (CAP), Grupo de Apoio Pedagógico (GAP), Núcleo de Apoio Pedagógico (NAP), }\end{array}$ & $95 \%$ \\
& \begin{tabular}{l} 
entre outros pela IES. \\
\cline { 2 - 3 }
\end{tabular} & $\begin{array}{l}\text { Apoio da IES à participação de docentes em projetos de pesquisa e eventos } \\
\text { científicos. }\end{array}$ \\
\cline { 2 - 3 } & $\begin{array}{l}\text { Apoio da IES à participação de docentes a processos educacionais (cursos stricto } \\
\text { sensu) de outras IES (dentro ou fora do Brasil). }\end{array}$ & $71 \%$ \\
\cline { 2 - 3 } & Promoção de eventos científicos que contemplem o ensino/docência. & $81 \%$ \\
\hline
\end{tabular}

Fonte: Dados da Pesquisa

Também foram solicitadas aos especialistas sugestões quanto a outros fatores, em cada uma das qualificações analisadas, segundo a sua própria experiência e conhecimento. A comissão de especialistas fez várias sugestões que podem contribuir para a qualificação dos docentes que ministram aulas de Contabilidade, em cada uma das três qualificações em análise. Essas sugestões foram acatadas e submetidas à análise da comissão, a partir da segunda rodada. Quanto à qualificação acadêmica, foram sugeridos os seguintes fatores:

- Reputação do programa de mestrado ou doutorado: refere-se ao prestígio do programa, como, por exemplo, o conceito na CAPES, no caso do Brasil.

- A qualidade da tese ou dissertação: refere-se ao desempenho alcançado pela tese ou dissertação defendida, como, por exemplo, a nota, conceito ou menção obtida na defesa do trabalho.

- Grupos de pesquisas: considera o envolvimento do docente em grupos de pesquisas que, efetivamente, produzam novos conhecimentos.

- Participar regularmente de eventos científicos da área: refere-se à participação do docente em congressos, seminários e encontros científicos, nos quais são discutidos temas atuais sobre a realidade contábil.

Adicionalmente, os participantes estrangeiros fizeram comentários, enfatizando a qualidade do programa, do quadro docente e da tese ou dissertação, o que é justificável, uma vez que a pós-graduação, no contexto anglo-saxônico, é bem mais desenvolvida do que no Brasil. Os pesquisadores brasileiros, por sua vez, enfatizam o envolvimento do docente no contexto da pesquisa (participação em grupos de pesquisas e de eventos científicos).

Ao discorrer sobre os fatores investigados, os especialistas destacaram a qualificação profissional como dimensão importante na formação do professor que ensina Contabilidade. Segundo eles,

- nas áreas de Ciências Sociais Aplicadas, é essencial a prática para o docente, uma vez que o "laboratório" de pesquisa, muitas vezes, é a empresa.

- a Contabilidade é uma Ciência Social Aplicada. A meu ver, é importante e necessário que os docentes de Contabilidade possuam vivência profissional. Essa vivência, aliada às qualificações identificadas na literatura, contribuem para enriquecer a docência.

Além dos argumentos acima destacados, a dimensão profissional também foi contemplada pelos especialistas, com quatro novos fatores, os quais são apresentados a seguir. 
- Experiência de atuação na área de gestão: refere-se à experiência do docente como tomador de decisão, usuário da informação contábil na gestão de empreendimentos.

- Possuir certificações profissionais nacionais: credencial profissional (registro no CRC) e/ou certificado de auditor independente (CVM), entre outras.

- Possuir certificações profissionais internacionais, como: CPA, CMA e ACCA (Association of Chartered Certified Accountants).

- Participar regularmente de eventos profissionais da área contábil: participação em eventos que possibilitem ao docente ficar em sintonia com as práticas profissionais vigentes.

A qualificação pedagógica também foi bastante enfatizada pelos especialistas. Em diversos momentos, pode-se notar a preocupação do grupo com essa dimensão, conforme os trechos abaixo:

- Aprender a ensinar é uma parte importante das responsabilidades de um professor. Essas habilidades precisam de aprimoramento e atualizações constantes no sentido de aplicar estratégias de ensino eficazes e condizentes com os diferentes estilos de aprendizagem.

- A profissão "professor" tende, muitas vezes, a acomodar o docente na posição de um 'especialista' de determinada disciplina, levando-o a entender que isso, aliado à reprodução de sua formação específica, é o bastante para ensinar. É necessário, dentro de uma formação pedagógica, que o professor do ensino superior seja conhecedor de conhecimentos e competências requeridos à docência universitária.

- $\quad[. .$.$] podem e devem ser desenvolvidos cursos sobre como preparar e elaborar apresenta-$ ções, seleção e uso de estratégias de ensino, entre outros. Entretanto, é preciso esclarecer que o esforço não pode ser apenas do professor. Mais de 90\% dos cursos de Ciências Contábeis, no Brasil, são em IES privadas no período noturno e, muitas vezes, as condições são desfavoráveis ou mesmo adversas.

Os especialistas sugeriram, ainda, cinco novos fatores sobre a qualificação pedagógica, os quais são apresentados a seguir.

- Participar regularmente em eventos da área pedagógica.

- Promoção de workshops entre os docentes para discussão sobre o ensino.

- Incentivar e apoiar a produção de livros didáticos na área de Contabilidade.

- Envolvimento do quadro docente na construção do projeto político-pedagógico do curso.

- Avaliação regular do quadro docente, por discentes e/ou por pares e/ou institucional.

Além dos fatores relativos às três qualificações investigadas neste estudo, outros fatores relacionados à qualificação docente foram captados na fala dos especialistas. Esses fatores estão relacionados à formação docente proporcionada pelo programa de mestrado ou doutorado, por meio de disciplinas didático-pedagógicas ou estágios docência. Nas palavras dos especialistas,

- professores de Contabilidade podem e devem desenvolver expertise para a atuação em sala de aula. Os programas stricto sensu devem valorizar mais este aspecto, apesar das atuais regras da CAPES;

- minimamente, cada programa stricto sensu deve ter uma disciplina específica (Didática do Ensino da Contabilidade, Metodologia do Ensino da Contabilidade ou outro nome); devem também instituir programas tipo o Programa de Aperfeiçoamento ao Ensino [PAE] da Universidade de São Paulo, ou mesmo estágios supervisionados nas IES de origem dos mestrandos e/ou doutorandos. 
Os depoimentos acima destacam possibilidades importantes na formação inicial do docente, conforme salientado na literatura (Miranda, 2010; Masetto, 2003). Os especialistas consideram, ainda, que a avaliação deve levar em conta a realidade da instituição em vez de avaliar cada um dos integrantes do corpo docente institucional.

\subsection{Segunda Rodada Delphi}

Para a realização da segunda rodada da técnica Delphi, considerou-se o nível de aceitabilidade, por parte da comissão de especialistas, dos fatores na primeira rodada (Cunha, 2007). Os fatores foram separados em dois grupos: a) fatores com baixa aceitabilidade - que obtiveram menos de $50 \%$ de concordância por parte dos especialistas; e b) fatores com média e alta aceitabilidade - que obtiveram $50 \%$ ou mais de aceitabilidade pela comissão de especialistas.

Desse modo, foram excluídos da lista cinco fatores, conforme apresenta a Tabela 1 . O primeiro, relativo à qualificação acadêmica, foi "título de especialista", que obteve $43 \%$ de concordância. O segundo e o terceiro, ambos relativos à qualificação acadêmica, foram "ser revisor de periódicos científicos ou parecerista" e "atuar em instituições de ensino superior com dedicação exclusiva", que obtiveram, respectivamente, os percentuais de concordância $48 \%$ e $38 \%$. Sobre esse último fator mencionado, considera-se surpreendente o alto índice de discordância, uma vez que a dedicação exclusiva existe exatamente para que o docente tenha tempo de se dedicar à pesquisa que, por sua vez, se traduz em qualificação acadêmica. Esse aspecto indica uma contradição, pois a comissão, ao mesmo tempo em que desvaloriza a dedicação exclusiva, concede $95 \%$ (o maior percentual) de concordância ao fator "apoio à participação de docentes em projetos de pesquisa e eventos científicos", na qualificação pedagógica.

O quarto fator excluído, pertencente à qualificação profissional "Participação em associações de classe ou órgãos reguladores (por exemplo: Conselhos de Contabilidade, Comissão de Valores Mobiliários, Banco Central, Comitê de Pronunciamentos Técnicos)", obteve 48\% de concordância entre os especialistas. O quinto fator excluído "curso de formação pedagógica stricto sensu (mestrado ou doutorado) em Educação", que faz parte da qualificação pedagógica, obteve $43 \%$ de concordância na comissão de especialistas, tendo sido o fator que causou maior polêmica entre os membros. As opiniões expressas a esse respeito foram as seguintes:

- Acredito que, uma vez optado pela profissão docente, não bastaria ter como qualificação acadêmica apenas um título específico, quer seja mestre ou doutor, mas, necessariamente, em EDUCAÇÃO.

- O professor de Contabilidade precisa se expor às aulas de Pedagogia, mas não se tornar, obrigatoriamente, um especialista nessa área. Pelo menos como regra, não.

- O mestrado e doutorado em Educação deve ser tão valorizado quanto os da área específica. Entretanto, não pode ser obrigatório e nem envolver todos os docentes. Mas um bom curso há de ter alguns profissionais dedicados ao campo da Pedagogia universitária, ligada à área de formação.

Uma nova lista, contendo 30 fatores compostos pelos 17 fatores remanescentes da primeira rodada e os 13 novos fatores sugeridos pelos especialistas, foi apresentada à comissão, na segunda rodada. Aos especialistas, foi solicitado que avaliassem o grau de importância de cada fator para a respectiva qualificação docente, atribuindo-lhes uma nota em uma escala de zero (menos importante) a dez (mais importante). 


\subsection{Terceira Rodada Delphi}

Ao final da terceira rodada, foi verificado que as respostas alcançaram a estabilidade recomendada pela literatura, pois apenas um fator obteve coeficiente de variação superior a 30\%. Assim, foram encerradas as rodadas da técnica Delphi. Os resultados apurados são apresentados na Tabela 2.

Tabela 2

\section{Grau de Importância dos Fatores}

\begin{tabular}{|c|c|c|c|}
\hline Fator & Escore & $\%$ & Classificação \\
\hline Avaliação regular do quadro docente por discentes e/ou por pares e/ou institucional. & 189 & $90 \%$ & $1^{\circ}$ \\
\hline Envolvimento do quadro docente na construção do projeto pedagógico do curso. & 187 & $89 \%$ & $2^{\circ}$ \\
\hline Título de doutor. & 186 & $89 \%$ & $3^{\circ}$ \\
\hline Experiência de atuação na profissão contábil (mínima de dois anos). & 184 & $88 \%$ & $4^{\circ}$ \\
\hline Promoção de workshops entre os docentes para discussão sobre o ensino. & 184 & $88 \%$ & $4^{\circ}$ \\
\hline Experiência como docente (mínimo de dois anos). & 182 & $87 \%$ & $5^{\circ}$ \\
\hline Participar regularmente de eventos científicos da área contábil. & 179 & $85 \%$ & $6^{\circ}$ \\
\hline $\begin{array}{l}\text { Curso de extensão para formação pedagógica (e.g. pedagogia universitária, cursos sobre } \\
\text { novas tecnologias educacionais). }\end{array}$ & 178 & $85 \%$ & $7^{\circ}$ \\
\hline Apoio à participação de docentes em projetos de pesquisa e eventos científicos. & 178 & $85 \%$ & $7^{\circ}$ \\
\hline Participar de grupos de pesquisas coesos e atuantes. & 178 & $85 \%$ & $7^{\circ}$ \\
\hline Título de mestrado. & 174 & $83 \%$ & $8^{\circ}$ \\
\hline Promoção de eventos científicos que contemplem o ensino/docência. & 173 & $82 \%$ & $9^{\circ}$ \\
\hline Projetos de pesquisas aplicadas (academia/mercado). & 173 & $82 \%$ & $9^{\circ}$ \\
\hline $\begin{array}{l}\text { Apoio à participação de docentes em processos educacionais (cursos stricto sensu) de } \\
\text { outras IES (dentro ou fora do Brasil). }\end{array}$ & 172 & $82 \%$ & $10^{\circ}$ \\
\hline Curso de formação pedagógica lato sensu (especialização) em educação. & 171 & $81 \%$ & $11^{\circ}$ \\
\hline $\begin{array}{l}\text { Experiência de atuação na área de gestão como tomador de decisão (usuário da } \\
\text { informação contábil). }\end{array}$ & 170 & $81 \%$ & $12^{\circ}$ \\
\hline A qualidade da tese ou dissertação defendida (conceito, nota ou menção obtida). & 170 & $81 \%$ & $12^{\circ}$ \\
\hline $\begin{array}{l}\text { Oferta de programas de preparação para docência Centro de Apoio Pedagógico (CAP), } \\
\text { Grupo de Apoio Pedagógico (GAP), Núcleo de Apoio Pedagógico (NAP), entre outros. }\end{array}$ & 170 & $81 \%$ & $12^{\circ}$ \\
\hline $\begin{array}{l}\text { Possuir publicações em periódicos científicos internacionais ou com Qualis/CAPES = A1, } \\
\text { A2, B1 ou B2. }\end{array}$ & 169 & $80 \%$ & $13^{\circ}$ \\
\hline Possuir publicações em outros periódicos científicos. & 166 & $79 \%$ & $14^{\circ}$ \\
\hline Participar regularmente de eventos profissionais da área contábil. & 164 & $78 \%$ & $15^{\circ}$ \\
\hline Consultorias, assessorias e pareceristas técnicos. & 163 & $78 \%$ & $16^{\circ}$ \\
\hline $\begin{array}{l}\text { A reputação do programa de doutorado/mestrado cursado e de seu corpo docente (e.g. } \\
\text { conceito do programa na CAPES). }\end{array}$ & 160 & $76 \%$ & $17^{\circ}$ \\
\hline Participação em associações ou órgãos de pesquisa (Exemplos: ANPAD, ANPCONT, CAPES). & 159 & $76 \%$ & $18^{\circ}$ \\
\hline Projetos de pesquisas relacionados ao ensino. & 154 & $73 \%$ & $19^{\circ}$ \\
\hline Incentivo e apoio à produção de livros didáticos na área de Contabilidade. & 153 & $73 \%$ & $20^{\circ}$ \\
\hline $\begin{array}{l}\text { Possuir certificações profissionais nacionais, como: credencial profissional (registro junto } \\
\text { ao CRC) e/ou certificado de auditor independente (CVM). }\end{array}$ & 151 & $72 \%$ & $21^{\circ}$ \\
\hline Participar regularmente em eventos da área pedagógica. & 151 & $72 \%$ & $21^{\circ}$ \\
\hline Projetos de extensão envolvendo academia e comunidade. & 150 & $71 \%$ & $22^{\circ}$ \\
\hline $\begin{array}{l}\text { Possuir certificações profissionais internacionais, como: Certified Public Accountants (CPA), } \\
\text { Certified Management Accountant (CMA) e Association of Chartered Certified Accountants } \\
\text { (ACCA) }\end{array}$ & 131 & $62 \%$ & $23^{\circ}$ \\
\hline
\end{tabular}

Fonte: Dados da Pesquisa 
O fator mais bem avaliado foi "Avaliação regular do quadro docente por discentes e/ou por pares e/ ou institucional", que obteve o escore de 189 pontos. Entretanto, houve algumas divergências no entendimento sobre a forma de realização da avaliação. Esse fator foi sugerido por quatro membros da comissão, na primeira rodada. Alguns deles mencionaram avaliação por pares, outros, por discentes, e um terceiro grupo não mencionou o tipo de avaliação. Na terceira rodada, ainda apareceram considerações sobre o fator "avaliação". Já o segundo fator mais bem avaliado "Envolvimento do quadro docente na construção do projeto político pedagógico do curso" também foi uma sugestão da comissão de especialistas e, semelhante ao primeiro, pertencia à qualificação pedagógica, tendo obtido 187 pontos de escore. O terceiro fator com maior número de pontos de escore (186) foi “Título de Doutor", relativo à qualificação acadêmica.

Ao analisar os coeficientes de variação, observa-se que os fatores com as menores variações, portanto, maior consenso, foram "Avaliação regular do quadro docente por discentes e/ou por pares e/ou institucional", com CV =9,1\% e "Consultorias, assessorias e pareceristas técnicos", com CV =11,9\%. O único fator que obteve alta variação foi "Possuir certificações profissionais internacionais, como: CPA, CMA e ACCA", com CV $=32 \%$. Esse fator foi, ainda, o que obteve o menor escore entre os especialistas (131 pontos).

Novamente é importante enfatizar que, ao convidar os membros para participarem da comissão, tomou-se o cuidado de contemplar uma ampla diversidade de professores, pesquisadores e profissionais, a fim de evitar resultados tendenciosos. Como o objetivo da pesquisa é analisar os fatores componentes das qualificações acadêmica, profissional e pedagógica dos docentes que ministram aulas nos cursos de Ciências Contábeis no Brasil, optou-se por realizar uma avaliação das respostas de subgrupos: comissão completa (21 especialistas), contadores brasileiros (9 especialistas), contadores estrangeiros (5 profissionais) e profissionais da área Educacional e do campo da Administração de Empresas (7 profissionais), conforme previsto na literatura (Cunha, 2007; Giovinazzo, 2001).

Tais análises permitem concluir que quando se observam as variáveis relacionadas à qualificação acadêmica (analisando a Figura 1 no sentido horário), os especialistas estrangeiros constituem o grupo que menos valoriza o título de mestrado, ainda que valorizem o título de doutor de forma semelhante aos demais grupos. Esse fato pode retratar a quantidade bastante superior de profissionais com títulos stricto sensu naqueles países, o que faz com que o título de mestrado seja menos valorizado do que no Brasil. Além disso, no exterior, em alguns países, é usual o título de mestrado ser visto como uma formação mais voltada para a preparação profissional do que propriamente acadêmica, em muitos não sendo inclusive necessário o mestrado concluído para ingressar no doutorado.

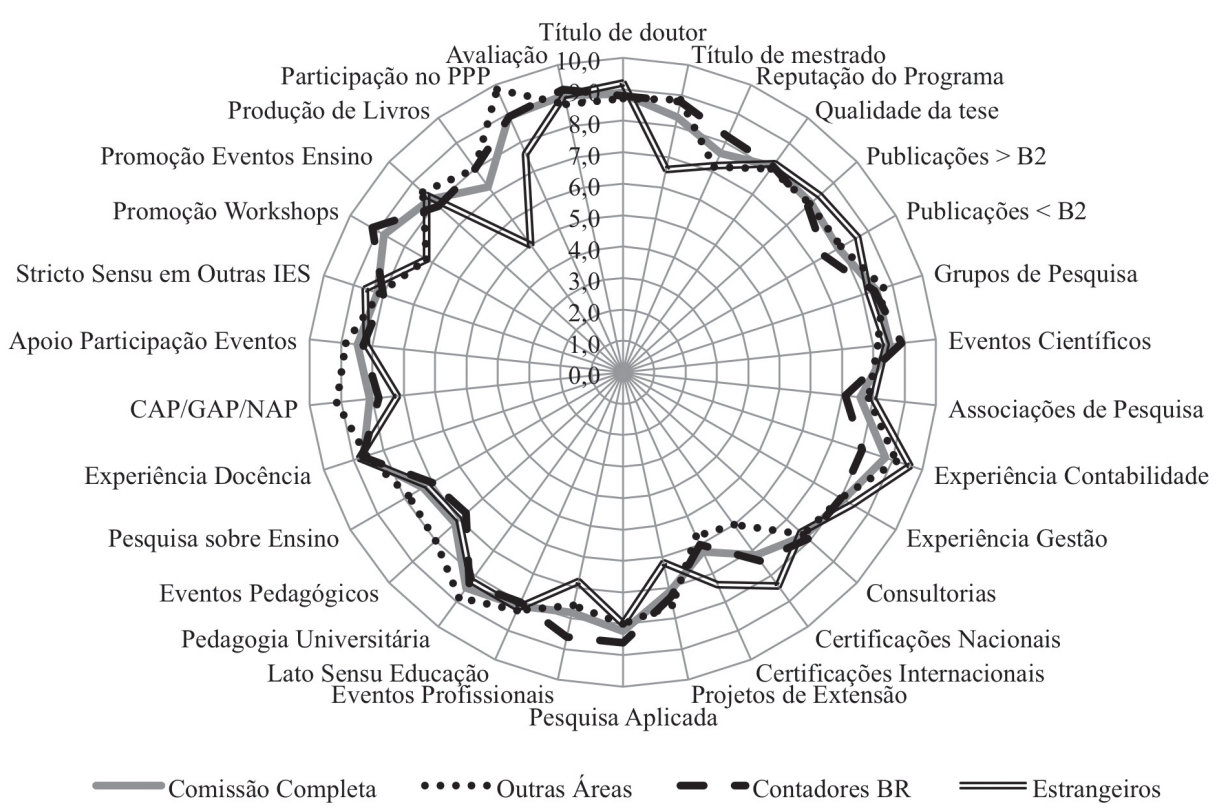

Figura 3. Comparativo dos Scores (\%) entre as Subcomissões e a Comissão Completa Fonte: Dados da Pesquisa 
Ao se analisarem as variáveis componentes da qualificação profissional, nota-se também que os especialistas estrangeiros atribuíram notas maiores que os demais à experiência profissional. Também se percebe que as certificações nacionais e internacionais são menos valorizadas pelos profissionais de outras áreas (Educação e Administração), enquanto que os profissionais estrangeiros constituem o grupo que menos valoriza a participação docente em projetos de extensão e em eventos profissionais da classe contábil e que, ainda, mais valorizam as credenciais profissionais nacionais. Essa diferença de valorização justifica-se pela importância que as credenciais profissionais possuem naqueles países. No caso da credencial CPA, por exemplo, o candidato deve ter pelo menos 150 horas de educação formal, além do curso superior e do próprio exame CPA, “[...] que é bastante difícil” (Lopes \& Martins, 2005, p. 105).

A qualificação pedagógica foi a que apresentou maiores diferenças. Como era de se esperar, os especialistas de outras áreas (notadamente da área Educacional) foram os que atribuíram, em média, as maiores notas às variáveis desse grupo, principalmente, à variável "participação no projeto político-pedagógico da instituição", cuja média foi de $98,6 \%$ para esse grupo. Os contadores estrangeiros atribuíram as menores notas aos itens: eventos da área pedagógica; pesquisas sobre ensino; participação em cursos de formação pedagógica; promoção de workshops; e produção de livros didáticos.

$\mathrm{Na}$ segunda e terceira rodadas, foi solicitado aos especialistas que atribuíssem pesos a cada uma das qualificações, conforme suas percepções. A Figura 4 apresenta os resultados apurados da comissão completa e subcomissões.

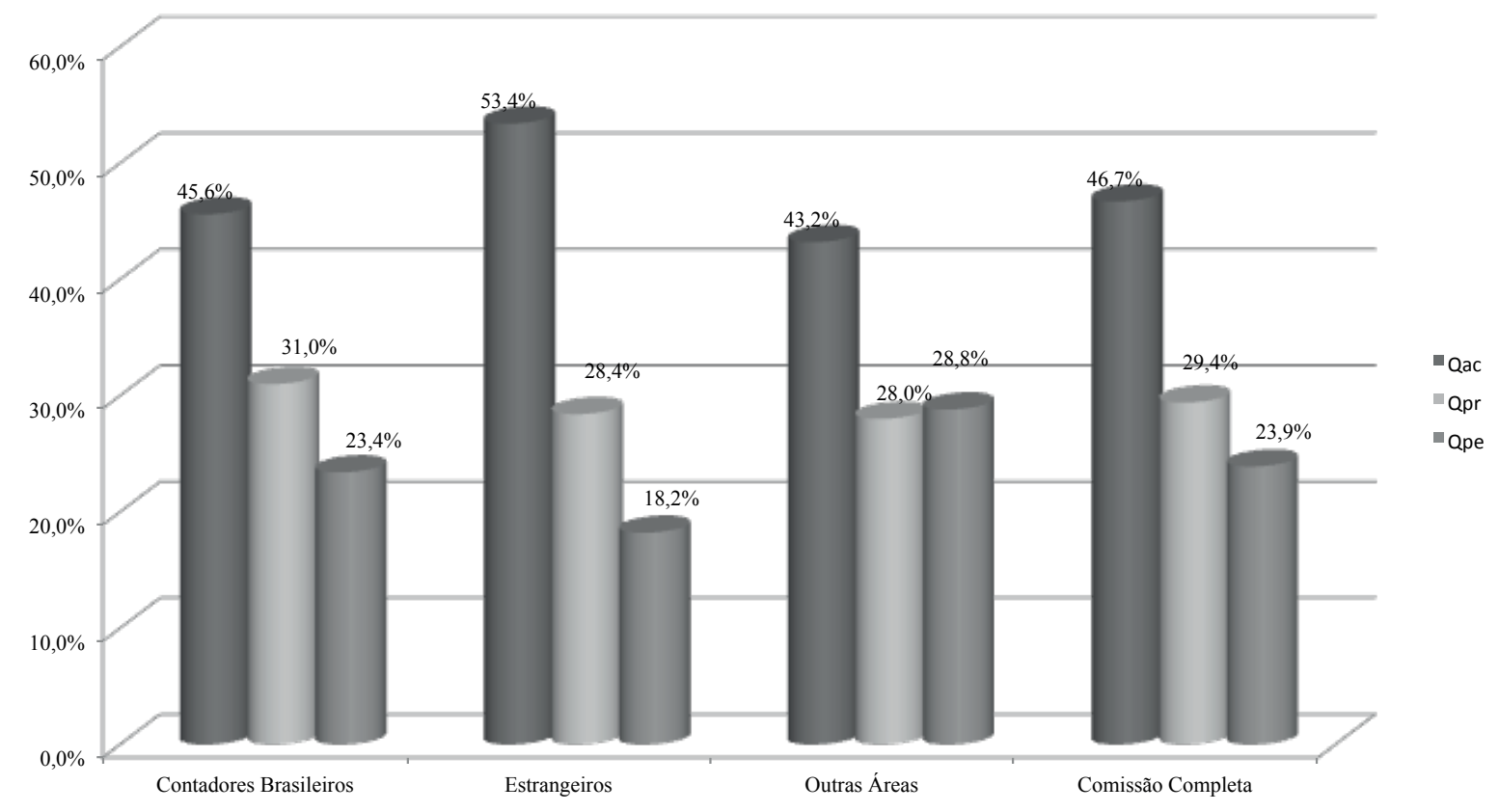

Figura 4. Pesos atribuídos pelos especialistas às qualificações docentes

Fonte: Dados da Pesquisa

Segundo a comissão de especialistas, a qualificação acadêmica é considerada a mais importante na formação do professor de Contabilidade, pois alcançou a média de 46,7\%. Esse tipo de qualificação é também o mais valorizado pelos especialistas estrangeiros participantes da pesquisa. Para esses, a qualificação acadêmica deveria representar mais da metade das qualificações necessárias ao ensino (53,4\%). Esse pensamento está em sintonia com os mecanismos de avaliação da AACSB (2010c), os quais exigem, no mínimo, 50\% de qualificação acadêmica do corpo docente em cursos na área de Contabilidade para que possam ser credenciados. 
O segundo tipo de qualificação docente, em termos de relevância, foi "qualificação profissional", que obteve uma média de 29,4\% na comissão de especialistas. Os contadores brasileiros são os especialistas que mais valorizam a qualificação profissional. Entre esses, o percentual médio foi de 31\%. Já os especialistas das áreas de Administração e Educação foram os que menos valorizaram esse tipo de qualificação. Esses resultados não se diferenciam muito do histórico apresentado nas avaliações da AACSB (2010b), cujos percentuais de qualificação profissional, entre 2006 e 2009, estão em torno de 32\%, enquanto os percentuais de qualificação acadêmica giram em torno de $61 \%$.

A qualificação pedagógica obteve os menores percentuais $(23,9 \%)$ na comissão completa. Os especialistas de outras áreas, principalmente, aqueles oriundos da Educação, são os que mais valorizam a qualificação pedagógica (28,8\%). Já os estrangeiros são os que menos valorizam esse tipo de qualificação. E, de fato, não existe um parâmetro internacional para comparar com a qualificação pedagógica, pois, nos critérios da AACSB (2010), a qualificação acadêmica contempla, também, os fatores relativos à qualificação pedagógica.

\section{Considerações Finais}

O presente estudo parte da problemática relacionada à definição das dimensões da qualificação do docente em Contabilidade no Brasil e seus respectivos fatores. Com levantamentos na literatura de três qualificações essenciais (acadêmica, profissional e pedagógica), o estudo procurou confirmar os fatores componentes de cada uma das respectivas qualificações por meio de uma comissão de especialistas nacionais e estrangeiros, utilizando-se a técnica Delphi.

Inicialmente, 22 fatores foram apresentados à comissão, sendo cinco desses excluídos após a primeira rodada, o que revela a oposição da comissão de especialistas a alguns aspectos da literatura consultada. Em outras palavras, para a comissão, o fato de o docente ter o "título de especialista", "ser revisor de periódicos científicos ou parecerista" ou "atuar em instituições de ensino superior com dedicação exclusiva" não o qualifica do ponto de vista acadêmico. Da mesma forma, a comissão entendeu que a "Participação em associações de classe ou órgãos reguladores (Exemplos: Conselhos de Contabilidade, Comissão de Valores Mobiliários, Banco Central, Comitê de Pronunciamentos Técnicos)" não é relevante à qualificação profissional do docente em Contabilidade. Os resultados também revelaram que, para a comissão, o docente qualificado do ponto de vista pedagógico não necessita ter "curso de formação pedagógica stricto sensu (mestrado ou doutorado) em Educação".

A participação dos especialistas foi efetiva em todas as rodadas, tendo eles acrescentados 13 novos fatores e vários comentários ao longo do processo. Além dos fatores sugeridos pela literatura, a comissão de especialistas acredita que a qualificação acadêmica deve considerar também: a reputação do programa de mestrado ou doutorado; a qualidade da tese ou dissertação; a participação em grupos de pesquisas; e a participação em eventos científicos da área. Sobre a qualificação profissional, a comissão deixou claro que as sugestões identificadas na literatura não são suficientes, considerando necessário que o docente profissionalmente qualificado tenha vários outros requisitos, que são: experiência de atuação na área de gestão; certificações profissionais nacionais, como credencial profissional (registro no CRC) e/ou certificado de auditor independente (CVM); certificações profissionais internacionais, como CPA, CMA e ACCA; e que participe regularmente de eventos profissionais da área contábil. Para a qualificação pedagógica, a comissão também acrescentou importantes fatores. Conforme a comissão, a referida qualificação deve contemplar os seguintes fatores: participação regular do docente em eventos da área pedagógica; apoio institucional na promoção de workshops entre os docentes para discussão sobre o ensino; incentivo e apoio à produção de livros didáticos na área de Contabilidade; envolvimento do quadro docente na construção do projeto político-pedagógico do curso e avaliação regular do quadro docente, por discentes e/ou por pares e/ou institucional. 
Na segunda e terceira rodadas, nenhum fator obteve percentual menor que 50\% de aceitação por parte da comissão. Portanto, todos os 30 fatores permaneceram até o fim da aplicação da técnica. Apenas um fator não obteve coeficiente de variação inferior a 30\%, ou seja, não alcançou o consenso da comissão. Assim, na terceira rodada, foi alcançado consenso em $97 \%$ dos fatores. Embora não seja regra, pode-se notar que os fatores que obtiveram as maiores médias também obtiveram os coeficientes de variação mais baixos, enquanto que os fatores com as menores médias, em geral, obtiveram os maiores coeficientes de variação.

Em linhas gerais, pode-se perceber que os especialistas estrangeiros valorizam mais a qualificação acadêmica (vide Gráfico 2) do que os demais, principalmente, a titulação de doutor e a participação em eventos científicos da área contábil. Já os contadores brasileiros são os que mais valorizam a formação profissional. Os especialistas com formação em Administração ou Educação são os que mais valorizam a qualificação pedagógica (conforme Gráfico 1 e Gráfico 2), o que pode ter ocorrido devido à formação deles. Dessa maneira, a formação acadêmica é o fator mais valorizado pela comissão completa, alcançando $46,7 \%$ entre os especialistas.

Os mecanismos de avaliação de instituições, professores e alunos, tanto no Brasil, quanto no cenário internacional (Brasil, 2008; Njoku et al., 2010; Ruff et al., 2009; Pierre et al., 2009; Annisette \& Kirkham, 2007; Kachelmeier, 2002), estão fortemente focados na produção científica, o que, muitas vezes, tem sido objeto de críticas por parte de muitos estudiosos (Almeida \& Pimenta, 2009; Cunha, 2006). Mas quando se analisa a opinião de especialistas (e também da AACSB e da CAPES), nota-se que é exatamente a pesquisa (formação acadêmica) que passa, necessariamente, pela titulação, a mais valorizada.

Isso ocorre porque as mudanças que afetam a profissão, como a adoção de padrões internacionais e os avanços tecnológicos, modificam o ensino na área contábil. A atuação profissional prioriza a aplicação técnica e a reprodução do conhecimento, não levando em conta os elementos que o futuro muito próximo reserva para os formandos: raciocínio crítico, capacidade de comunicação, capacidade de realizar julgamentos, etc. Cada vez mais, problemas estruturados ou semiestruturados (técnicos) são absorvidos pela "máquina", em função dos avanços tecnológicos. Em outras palavras, o docente com qualificação exclusivamente técnica, pela própria natureza da atuação, certamente não estará preparado para, em sala de aula, ajudar os estudantes a conquistarem as competências que serão cobradas deles nesse "novo mercado". Portanto, o que pode levar as IES a modificarem o cenário, em longo prazo, é, exatamente, o investimento em qualificação acadêmica.

Esses resultados sugerem a necessidade de políticas de apoio à pós-graduação stricto sensu em Ciências Contábeis no Brasil, uma vez que é por meio da titulação que se pode alcançar a qualificação acadêmica. Apontam também a necessidade de conscientização dos próprios docentes sobre a importância da qualificação docente em sua formação como professor.

Por se tratar de um tema amplo e complexo, novas pesquisas se fazem necessárias. Entre elas, sugere-se: (a) investigar a relação entre as qualificações acadêmica, profissional e pedagógica e os resultados do Exame de Suficiência do Conselho Federal de Contabilidade (quando divulgados) e (b) investigar as três qualificações, pesquisadas neste estudo, nos cursos de Ciências Contábeis, tendo como sujeitos de pesquisa os próprios docentes, com o intuito de propor uma escala de mensuração da qualificação docente em cursos de Ciências Contábeis.

\section{Referências}

Almeida, M. I. de, \& Pimenta, S. G. (2009). Pedagogia universitária: valorizando o ensino e a docência na Universidade de São Paulo. In: Almeida, M. I. de, \& Pimenta, S. G. (Orgs.). Pedagogia universitária. São Paulo: Edusp.

Andere, M. A., \& Araújo, A. M. P. (2008, setembro/dezembro). Aspectos da formação do professor de ensino superior de Ciências Contábeis: uma análise dos programas de pós-graduação. Revista de Contabilidade e Finanças, 19(48), pp. 91-102. 
Annisette, M., \& Kirkham L. M. (2007). The advantages of separateness explaining the unusual profession-university link in English Chartered Accountancy. Critical Perspectives on Accounting, 18(1), pp.1-30.

Brasil. Instituto Nacional de Estudos e Pesquisas Educacionais. Diretoria de Informações e Estatísticas Educacionais (2008). Cálculo do Conceito ENADE. Recuperado em 18 agosto, 2011, de http://www. inep.gov.br

Bouillon, M. \& Ravenscroft, S. (2010). Undergraduate Preparation and Dissertation Methodologies of Accounting PhDs. over the Past 40 Years. Global Perspectives in Accounting Education, 7, pp.19-29.

Catapan, A.; Colauto, R. D.; Sillas, E.P. (2011). Análise da percepção dos discentes sobre os docentes exemplares de contabilidade em IES públicas e privadas. In: V Congresso da AnpCONT. Anais... Vitória, ES, Brasil.

Cunha, J. V. A. (2007). Doutores em Ciências Contábeis da FEA/USP: análise sob a óptica da teoria do capital humano. Tese de doutorado em Ciências Contábeis, Programa de Pós-Graduação em Ciências Contábeis, Departamento de Contabilidade e Atuária, FEA/USP, São Paulo, Brasil.

Cunningham, B. M. (2008, February). Using action research to improve learning and the classroom learning environment. Issues in Accounting Education, 23(1), pp.1-30.

Czinkota, M. R.; \& Ronkainen, I. A. (2005). International business and trade in the next decade: report from a Delphi study. Journal of World Business, 40(4), pp.111-23.

Fink, A.; Kosecoff, J.; Chassin, M. \& Brook, R. (1984). Consensus Methods: Characteristics and Guidelines for Use. American Journal of Public Health, 74(9), pp. 979-983.

Frecka, T. J.; \& Reckers, P. M. J. (2010). Rekindling the Debate: What's Right and What's Wrong with Masters of Accountancy Programs: The Staff Auditor's Perspective. Issues in Accounting Education, 25(2), pp. 215-226.

Geary, W.; Kutcher, E. \& Porco, B. (2010). Partnering with Practice: Staffing to Achieve Excellence. Accounting Education, 25(2), pp.199-213.

Giovinazzo, R. (2001). A. Modelo de aplicação da metodologia Delphi pela internet - vantagens e ressalvas. Administração On Line, 2(2).

Grisham, T. (2009). The Delphi technique: a method for testing complex and multifaceted topics. International Journal of Managing Projects Business, 2(1), pp. 112-130.

Harmer, B. M. (2009). Teaching in a contextual vacuum: lack of prior workplace knowledge as a barrier to sense making in the learning and teaching of business courses. Innovations in Education and Teaching International, 46(1), pp. 41-50.

Heijden, B. I. J. M. (2003). Organizational influences upon the development of occupational expertise throughout the career. International Journal of Training \& Development, 7(3), pp. 142-165.

Kachelmeier, S. J. (2002). Defense of accounting education. The CPA Journal, 72(10).

Libâneo, J. C. (2009). Conteúdos, formação de competências cognitivas e ensino com pesquisa: unindo ensino e modos de investigação. Cadernos de Pedagogia Universitária, São Paulo, Edusp, 11.

Lopes, A. B; \& Martins, E. (2005). Teoria da Contabilidade: uma nova abordagem. São Paulo: Atlas.

Lowman, J. (2007). Dominando as técnicas de ensino. São Paulo: Atlas.

Machado, N. J. (2011). Educação - Microensaios em mil toques. Vol. III. São Paulo: Escrituras Editora.

Marshall, P. D., Dombrowski, R., Garner, M., \& Smith, K. (2010, June). The Accounting Education Gap. The CPA Journal, 80(6), pp. 6-10.

Martins, G. A. \& Theóphilo, C. R. (2007). Metodologia da Investigação Científica para Ciências Sociais Aplicadas. São Paulo: Atlas 
Masetto, M. T. (2003). Competência Pedagógica do Professor Universitário. São Paulo: Summus.

Miley, F. (2009, august) The storytelling project: innovating to engage students in their learning. Higher Education Research \& Development, 28(4), pp. 357-369.

Miranda, G. J., Casa Nova, S., \& Cornacchione, E. (2012, maio/agosto). Os saberes dos professores referência no ensino de Contabilidade. Revista de Contabilidade \& Finanças, 23(59), pp.142-153.

Miranda, G. J. (2010, maio/agosto). Docência universitária: uma análise das disciplinas na área da formação pedagógica oferecidas pelos programas de pós-graduação stricto sensu em Ciências Contábeis. REPEC, 4(2), pp. 81-98.

Njoku, J. C., Heijden, B. I. J. M., \& Inanga, E. L. (2010). Fusion of expertise among accounting faculty: Towards an expertise model for academia in accounting. Critical Perspectives on Accounting, 21(1), pp. 51-62.

Pierre, K. St., Wilson, R. M. S., Ravenscroft, S. P., Rebele, J. E. (2009, May).The role of accounting education research in our discipline - an editorial. Issues in Accounting Education, 24(2), pp. 112-130.

Ruff, M., Thibodeau, J. C., \& Bedard, J. C. (2009, March). A Profession's Response to a Looming Shortage: Closing the Gap in the Supply. Journal of Accountancy, 207(3), pp. 36-40.

Shulman, L. S. (2005). Conocimiento y enseñanza: fundamentos de la nueva reforma. Profesorado. Revista de Currículum y formación del profesorado, 9(2), pp. 1-30.

Shulman, L. S. (1986). Those Who Understand: Knowledge Growth in Teaching. Educational Researcher, 15(2), pp. 4-14.

Slomski, V. G. (2009). Saberes que fundamentam a prática pedagógicas dos professores de Ciências Contábeis. Revista Brasileira de Contabilidade, 39(180), pp. 119-140.

Slomski, V. G., \& Martins, G. A. (2008, outubro/dezembro). O conceito de professor investigador: os saberes e as competências necessárias à docência reflexiva na área contábil. Revista Universo Contábil, Blumenau, 4(4), pp. 06-21.

The Association to Advance Collegiate Schools of Business. (2010a). Data and Research. Recuperado em 20 agosto, 2010, de $h t t p: / / w w w . a a c s b . e d u / d a t a a n d r e s e a r c h / r e p o r t s / d e f a u l t . a s p .$.

The Association to Advance Collegiate Schools of Business. (2010b). Accreditation. Eligibility Procedures and Accreditation Standards for Business Accreditation. Recuperado em 20 agosto, 2010, de http:// www.aacsb.edu/ /media/C7E5BE54802D4787A3BF227188E0C3BB.ashx.

The Association to Advance Collegiate Schools of Business. (2010c). Publications: AQ/PQ Status: Establishing Criteria for Attainment and Maintenance of Faculty Qualifications-An Interpretation of AACSB Standards. Recuperado em 20 agosto, 2010, de $h t t p: / / w w w . a a c s b . e d u / p u b l i c a t i o n s / p a p e r s /$.

Trapnell, J. E., Mero, N., Williams, J. R., \& Krull Jr, G. W. (2009, November). The Accounting Doctoral Shortage: Time for a New Model. Issues in Accounting Education, 24(4), pp. 427-432.

Vianna, N. W. H. (1989). Subjetividade no processo de previsão. São Paulo, 1989. Tese (Doutorado em Administração) - Programa de Pós-Graduação em Administração, Departamento de Administração, Faculdade de Economia e Administração da Universidade de São Paulo.

Volpato, G. (2009). Marcas de profissionais liberais que se tornaram professores-referência. Revista Brasileira de Estudos Pedagógicos, 90(225), pp. 333-351. 